\title{
Association between health insurance enrolment and maternal health care service utilization among women in Ethiopia
}

\author{
Abdu Seid ${ }^{1 *}$ (D) and Mohammed Ahmed ${ }^{2}$
}

\begin{abstract}
Background: Health insurance was considered as the third global health transition which can increase access to health care services by eliminating monetary obstacles to maternal health care use, particularly in emerging nations. Hence, this study aimed to assess the association between health insurance enrolment and maternal health care service utilization among women in Ethiopia.

Methods: A cross-sectional study was conducted using the 2016 Ethiopia Demographic and Health Survey (EDHS) data set. About 4278 mothers who had delivered at least one child in the last five years of the survey were selected in the study. Multivariate logistic regression analysis was performed to measure the relationship between health insurance enrolment and maternal health care service utilization by controlling confounders An adjusted odds ratio with a 95\% confidence interval and $p$-values $<0.05$ were well-thought-out to state the imperative association.

Results: The overall health insurance coverage among the women was 4.7\%. About, 18.1\% of women from households in the poorest wealth quantile had no health insurance coverage for maternal health care services. Moreover, $84 \%$ of women lived in a rural area did not enclose by health insurance. According to multivariate logistic regression, the likelihoods of ANC utilization were 1.54 times (AOR: 1.54; 95\% Cl: 1.06-2.25) higher among mothers who were enrolled in health insurance compared to their counterparts. In the same vein, the likelihoods of been attended by a skilled birth attendant were 1.84 times (AOR: 1.84; 95\% Cl: 1.1-3.08) higher among mothers who were enrolled in health insurance.

Conclusions: This study has shown that women enrolled in health insurance were associated with skilled delivery and recommended ANC utilization than women who did not enroll in health insurance. Health insurance enrolment enterprises must be available to all pregnant women, particularly those of poorer socioeconomic rank.
\end{abstract}

Keywords: Health insurance enrolment, Maternal health care, Ethiopia

\footnotetext{
* Correspondence: abdus3536@gmail.com

${ }^{1}$ Department of Midwifery, Woldia University, Woldia, Ethiopia

Full list of author information is available at the end of the article
}

(c) The Author(s). 2021 Open Access This article is licensed under a Creative Commons Attribution 4.0 International License, which permits use, sharing, adaptation, distribution and reproduction in any medium or format, as long as you give appropriate credit to the original author(s) and the source, provide a link to the Creative Commons licence, and indicate if changes were made. The images or other third party material in this article are included in the article's Creative Commons licence, unless indicated otherwise in a credit line to the material. If material is not included in the article's Creative Commons licence and your intended use is not permitted by statutory regulation or exceeds the permitted use, you will need to obtain permission directly from the copyright holder. To view a copy of this licence, visit http://creativecommons.org/licenses/by/4.0/ The Creative Commons Public Domain Dedication waiver (http://creativecommons.org/publicdomain/zero/1.0/) applies to the data made available in this article, unless otherwise stated in a credit line to the data. 


\section{Background}

To escalate access to maternal health care services in developing countries, health insurance has paramount importance through tackling financial barriers [1-3]. According to the World Health Organization's (WHO) global agenda on Universal Health Coverage (UHC), all people should get comprehensive healthcare services at a reasonable cost and without monetary hardship by avoiding disastrous healthcare payment [4], which is a serious component of countrywide health policies in many low and middle-income nations [5]. Developing nations are experiencing reformation to expand their healthcare supporting mechanisms which able to increase the health care service utilization effectively and efficiently [6, 7]. Besides, the post-2015 Sustainable Development Goals (SDGs) have projected a new target to decrease the global Maternal mortality ratio (MMR) to 70 per 100,000 live births by $2030[8,9]$. Likewise, the Ethiopian government launched a health sector development program for 2010-2015 which includes communitybased health insurance (CBHI) for citizens and social health insurance for formal sectors to increase access to health care through risk pooling [10].

Recent evidence indicates that the higher frequency of antenatal care service utilization has a significant impact in reducing the probability of stillbirths, MMR, and perinatal deaths by eight per 1000 births as compared to four visits [11]. MMR in Ethiopia was 871 in 2000 EDHS, 676 in 2011 EDHS, and 412 in 2016 per 100,000 live births which is an insignificant change over the last decades [12]. Obstetrics complications like antepartum bleeding, postpartum bleeding, dystocia, preeclampsia, puerperal infection, and unsafe abortion were associated with maternal death in Ethiopia [13]. Additionally, delays in health-seeking behavior, accessing and receiving care for obstetric emergencies, financial, and health servicerelated factors were also mentioned as contributing factors to maternal death $[13,14]$. The crude domestic product (GDP) per individual in Ethiopia become approximately US\$360 with a growth rate of $7-8 \%$ in a year, and about $30 \%$ of its population surviving under the national poverty line, and a huge percentage of health costs funded via out-of-pocket many bills $[15,16]$. Then, out-of-pocket expenses leftovers a chief supply of health financing for the Ethiopian population and it is a substantial obstacle for gain access to and using maternal health care services $[17,18]$.

Therefore, the implementation of health insurance enrolment can be the potential health bankrolling system in minimizing out-of-pocket fees, mainly in the place where numerous persons live in rural parts of Ethiopia [19].

Various studies showed that the effect of health insurance coverage on the usage of maternal healthcare services could validate the effective association among rural and women who had low income hence insurance leads to a $9-11 \%$ higher likelihood of using ANC, skilled delivery, and PNC utilization [20-22]. Likewise, a research finding done in Tanzania discovered that taking health insurance was positively associated with the recommended timing of ANC and skilled delivery practice [23]. Evidence from Gabon and Ghana showed that women's enrolment in health insurance can increase the use of maternal healthcare [24, 25]. Besides, maternal healthcare use could be affected by health system factors, wealth index, residence, history of previous birth complications, number of children, transportation and, religion [26-31].

Unfortunately, no studies conducted in Ethiopia so far to measure the relationship between health insurance enrolment and maternal health care service utilization among Ethiopian women to know the extent of increasing maternal health care service utilization gained from insurance policies, which limits in reaching convincing results. So, this study is designed to measure the relationship between health insurance enrolment and utilization of maternal health care services in Ethiopia using a recent version of nationally representative data.

\section{Methods}

\section{Data and sampling}

This study was performed using national representative recorded data from the 2016 Ethiopia Demographic and Health Survey (EDHS). A full clarification of the data source, strategy, and methods of the survey become observed elsewhere [12]. This study used Woman's data which was gained from all women aged 15-49 in carefully chosen houses. The women's sample involves 15,683 women ages $15-49$. Finally, weighting adjustment was done by considering the sampling procedure, Therefore, all women who delivered at least one child in the last five years (4278 women) before the survey were included.

\section{Study variables}

The dependent variable of this study was maternal healthcare service utilization, which involved antenatal care (ANC), skilled birth, and postnatal care (PNC). ANC is the care given by skilled health professionals to gravid women and adolescent girls to safeguard the quality healthcare for both mom and fetus throughout her pregnancy [32]. Even though it is not practically applicable in Ethiopia, the new 2016 WHO guideline on ANC recommended that pregnant women should get eight contacts; which their first communication in the first 12 weeks' gestation and next contacts should be done at 20, 26, 30, 34, 36, 38 and 40 weeks of pregnancy $[11,32]$. Skilled delivery is having birth health institutions 
through qualified healthcare experts [33]. PNC is the care which given for the women by skilled healthcare expert after delivery [34]. Skilled delivery and postnatal care were coded 'yes/no' based on whether the women have gotten the service or not. Antenatal care was dichotomized based on WHO recommendations: those who had four or more antenatal visits were categorized as "complete recommended ANC" and others who had less than four as categorized as "not complete recommended ANC". The principal exposure variable of this study was health insurance enrolment which dichotomized as (yes/no). Ethiopia has different types of health insurance which include social insurance, employer-based insurance, communitybased insurance, and privately purchased commercial insurance. Those women enrolled in at least one of the types of health insurance for their last birth depicted above were considered as having health insurance coverage otherwise not.

Other independent variables have been carefully chosen from a literature assessment [26-31] on factors related to maternal health care service utilization which include; age, educational status, marital status, resident, wealth index, occupation, media access, distance to the health facility, pregnancy intention, and the number of offspring. The wealth index become labeled into five groups (the poorest, poorer, middle, richer and richest) which were found from 2016 EDHS.

\section{Data processing and analysis}

Descriptive statistical findings and weighted proportions of socio-demographic data have been computed related to health insurance and maternal healthcare utilization. Rao scot chi-square analysis was carried out to pick contenders for the multivariate model. All covariates of $P$-values of $<0.25$ had been entered all together into the multiple regression models. Adjusted odds ratios (AOR) had been used to state the significant relationship. The analysis had been done using SPSS version 24. Sample weighting has been done to manage the probabilities of sampling through strata and clusters.

In our study, the magnitude of the Variable inflation factor (VIF) was used to differentiate the multicollinearity issue. Even though no official standards exist for determining when a VIF is very huge, general cut-off values, such as VIF $\geq 5$ or VIF $\geq 10$; are usually used to govern [35]. In this study, the magnitudes of VIF for ANC, skilled delivery, and PNC were 3.5, 4.3, and 4.86 respectively; which shows that no multicollinearity issue is found.

\section{Results}

Maternal health insurance and related characteristics About 4278 samples of women who delivered in the past 5 years preceding the survey were included in the study and analyzed. According to this finding, the overall health insurance coverage among women was $4.7 \%$. According to this finding, health insurance coverage was quite different by their education level, occupation, wealth index, marital status, and place of residence. Maternal health insurance coverage decreased from non-educated women to secondary and above level (66.9 to $5.3 \%, p<0.042$ ). Likewise, $18.1 \%$ of women from households in the poorest wealth quintile had no health insurance coverage for maternal health care services. Moreover, $84 \%$ of women who are not covered by health insurance live in rural areas. Similarly, $91 \%$ of currently in a union or married women had no health insurance coverage. The likelihood of having health insurance was higher among those aged 25-34years and among women who had $\geq 5$ children. Additionally, more than half of (51.6\%) of women who are not working were not under the health insurance enrolment scheme (Table 1).

\section{Maternal health care service utilization}

Around 95, 95.2, and 94.7\% of women who had no health insurance enrolment did not attend complete the recommended ANC visit, skilled delivery, and postnatal care service utilization respectively. Moreover, 66.7, $60.5 \%$, and 24.8 mothers aged $25-34$ years had attended the recommended ANC, skilled delivery, and PNC correspondingly. Similarly, $61.8,71.8$, and $58.9 \%$ of mothers who did not attend formal education did not receive ANC, skilled delivery, and PNC respectively. Likewise, $87.9,96.7$, and $84.8 \%$ of mothers residing in rural areas had not taken the recommended ANC visit, skilled delivery, and PNC respectively. Additionally, 67.4, 73.9, and $64.2 \%$ of women had no media access and did not receive the recommended number of ANC, skilled delivery, and postnatal care service correspondingly.

A higher proportion of women who in the richest quintile class received recommended ANC visit, skilled delivery, and PNC service $(42.7,42.2$, and $34.9 \%)$ respectively. Furthermore, 90.6, 90.2, and $90.7 \%$ of currently in a union or married women received recommended ANC, skilled delivery, and PNC service respectively.

In bivariate analysis, health insurance enrolment had a significant association with antenatal care, skilled delivery, and postnatal care service utilization (Table 2).

\section{Association between health insurance enrolment and maternal health care service utilization}

All the variables were entered into multivariate logistic regression analysis. After adjusted for possible confounders by logistic regression, health insurance was positively associated with ANC and skilled delivery.

According to multivariate logistic regression, the odds of ANC utilization were 1.54 times (AOR: 1.54 ; $95 \%$ CI: 1.06-2.25) higher among mothers who were enrolled in 
Table 1 The distribution of respondents related to socio-demographic characteristics and health insurance coverage $(n=4278)$

\begin{tabular}{|c|c|c|c|c|}
\hline \multirow[t]{2}{*}{ Variable } & \multirow[t]{2}{*}{ Categories } & \multicolumn{2}{|c|}{ Maternal health insurance } & \multirow{2}{*}{$\begin{array}{l}\text { Chi-square } \\
p \text {-value }\end{array}$} \\
\hline & & Not insured (\%) & Insured (\%) & \\
\hline \multirow[t]{4}{*}{ Age } & $15-19$ & $305(6.60)$ & $7(4.60)$ & 0.006 \\
\hline & $20-24$ & $905(20.90)$ & $22(12.0)$ & \\
\hline & $25-34$ & $2425(60.8)$ & $134(64.0)$ & \\
\hline & $35-49$ & $444(11.80)$ & $36(19.30$ & \\
\hline \multirow[t]{4}{*}{ Educational status } & No education & $2185(57.30)$ & $110(66.9)$ & 0.042 \\
\hline & Primary & $1258(31.50)$ & $44(22.60)$ & \\
\hline & Secondary & $416(7.30)$ & $21(5.10)$ & \\
\hline & Higher & $220(3.90)$ & $24(5.30)$ & \\
\hline \multirow[t]{3}{*}{ Marital status } & Never in union & $52(1.2)$ & $4(1.60)$ & 0.009 \\
\hline & Currently in union & $3653(91.0)$ & $184(95.0)$ & \\
\hline & Formerly in union & $374(7.80)$ & $11(3.40)$ & \\
\hline \multirow[t]{2}{*}{ Residence } & Urban & $1055(16.0)$ & $55(16.70$ & 0.86 \\
\hline & Rural & $3024(84.0)$ & $144(83.30)$ & \\
\hline \multirow[t]{5}{*}{ Wealth index } & Poorest & $1126(18.10)$ & $15(6.0)$ & 0.008 \\
\hline & Poorer & $633(19.8)$ & $31(18.60)$ & \\
\hline & Middle & $603(21.40)$ & 49(27.0) & \\
\hline & Richer & $541(19.60)$ & $40(27.30)$ & \\
\hline & Richest & $1176(21.0)$ & $64(21.10)$ & \\
\hline \multirow[t]{2}{*}{ Occupation } & Not Working & $2170(51.60)$ & $54(31.20)$ & 0.001 \\
\hline & Working & $1909(48.40)$ & $145(68.80)$ & \\
\hline \multirow[t]{2}{*}{ Media access } & No & $2446(63.10)$ & $96(55.10)$ & 0.097 \\
\hline & Yes & $1633(36.90)$ & $103(44.90)$ & \\
\hline \multirow[t]{2}{*}{ Distance } & Big problem & $2014(54.40)$ & $65(38.60)$ & 0.003 \\
\hline & Not a big problem & $2065(45.60)$ & $134(61.40)$ & \\
\hline \multirow[t]{3}{*}{ Pregnancy intension } & Then & $3272(76.10)$ & $150(74.60)$ & 0.868 \\
\hline & Later & $537(15.60)$ & $32(15.80)$ & \\
\hline & No more & $270(8.40)$ & $17(9.60)$ & \\
\hline \multirow[t]{3}{*}{ Parity } & One & $1424(31.60)$ & $46(20.10)$ & 0.006 \\
\hline & $2-4$ & $1472(36.60)$ & $80(39.80)$ & \\
\hline & $>=5$ & $1183(31.80)$ & $73(40.10)$ & \\
\hline
\end{tabular}

health insurance. In the same vein, the odds of been attended by a skilled birth attendant were 1.84 times (AOR: 1.84; 95\% CI: 1.1-3.08) higher among mothers who were enrolled in health insurance. Besides, mothers aged 25-34 compared to 15-19 years had approximately 2 times (AOR: 2.03; 95\% CI: 1.15-3.58) higher odds of ANC service utilization.

Regarding educational status, the odds of ANC service utilization were 1.38 (AOR: 1.38; 95\% CI: 1.05-1.81), 1.57(AOR: 1.57; 95\% CI: 1.02-2.42), 2.1(AOR: 2.10; 95\% CI: $1.27-3.42)$ times higher among women attended primary, secondary and higher education, respectively compared to non-educated one. Likewise, the odds of been attended by a skilled birth attendant were 1.79 (AOR: 1.79; 95\% CI: 1.43-2.24), 4.84 (AOR: 4.84; 95\% CI: 2.89 8.90), 6.82(AOR: 6.28; 95\% CI: 3.18-14.6) times higher among women attended primary, secondary and higher education, respectively compared to non-educated one. Moreover, mothers residing in an urban area compared to rural residents had 4.74 (AOR: 4.74; 95\% CI: (2.628.57) times higher odds of been attended by skilled birth attendants.

The odds of recommended ANC and PNC utilization were 1.45(AOR: 1.45 ; 95\% CI: 1.08-1.95), and 1.67 times (AOR: 1.67; 95\% CI: 1.05-2.64) higher among mothers who accessed media compared to its counterparts. The 
Table 2 Bivariate analysis to assess the relationship between the independent variables and maternal health care service utilization $(n=4278)$

\begin{tabular}{|c|c|c|c|c|c|c|c|c|c|}
\hline \multirow[t]{2}{*}{ Variables } & \multicolumn{2}{|c|}{ Recommended ANC } & \multirow[t]{2}{*}{$P$ value } & \multicolumn{2}{|c|}{ Skilled Delivery } & \multirow[t]{2}{*}{$P$ value } & \multicolumn{2}{|c|}{ Received PNC } & \multirow[t]{2}{*}{$P$-value } \\
\hline & No (\%) & Yes (\%) & & No (\%) & Yes (\%) & & No (\%) & Yes (\%) & \\
\hline \multicolumn{10}{|l|}{ Health insurance } \\
\hline No & $3121(95.0)$ & 958(92.4) & 0.001 & $2239(95.2)$ & 1840(93.4) & 0.09 & $3773(94.7)$ & 306(91.5) & 0.06 \\
\hline Yes & $126(5.0)$ & $73(7.6)$ & & $76(4.8)$ & $123(6.6)$ & & $169(5.3)$ & $30(8.5)$ & \\
\hline \multicolumn{10}{|l|}{ Age } \\
\hline $15-19$ & $259(6.9)$ & $53(4.6)$ & 0.013 & $161(6.0)$ & $151(7.2)$ & 0.000 & $297(6.6)$ & $15(4.9)$ & 0.45 \\
\hline $20-24$ & $716(20.5)$ & 211(19.9) & & $437(17.1)$ & $490(25.7)$ & & $861(20.1)$ & $66(24.8)$ & \\
\hline $25-34$ & 1870(59.6) & $689(66.7)$ & & $1360(61.2)$ & $1199(60.5)$ & & $861(20.1)$ & $66(24.8)$ & \\
\hline $35-49$ & $402(12.9)$ & $78(8.8)$ & & $357(15.7)$ & $123(6.6)$ & & $2344(61.0)$ & 215(59.4) & \\
\hline \multicolumn{10}{|l|}{ Education } \\
\hline No education & 1962(61.8) & $333(40.0)$ & 0.000 & $1673(71.8)$ & $622(35.5)$ & 0.000 & 2154(58.9) & $141(43.5)$ & 0.001 \\
\hline Primary & $947(30.1)$ & $355(35.3)$ & & $560(26.1)$ & $742(38.9)$ & & 1197(30.7) & 105(36.1) & \\
\hline Secondary & $240(5.6)$ & 197(14.1) & & $71(1.7)$ & $366(15.7)$ & & $386(6.8)$ & $51(12.0)$ & \\
\hline Higher & $98(2.5)$ & 146(10.6) & & $11(0.4)$ & $233(9.8)$ & & $205(3.7)$ & $39(8.3)$ & \\
\hline \multicolumn{10}{|l|}{ Marital status } \\
\hline Never in union & $34(0.9)$ & $22(2.3)$ & 0.029 & $14(0.7)$ & $42(1.9)$ & 0.041 & $50(1.2)$ & $6(1.7)$ & 0.74 \\
\hline Currently union & $2921(91.3)$ & 916(90.6) & & 2109(91.8) & 1728(90.2) & & 3544(91.3) & 293(90.7) & \\
\hline Formerly union & $292(7.7)$ & $93(7.0)$ & & $192(7.4)$ & $193(7.9)$ & & $348(7.6)$ & $37(7.6)$ & \\
\hline \multicolumn{10}{|l|}{ Residence } \\
\hline Urban & $565(12.1)$ & $545(33.5)$ & 0.000 & $143(3.3)$ & $967(36.4)$ & 0.000 & $984(15.2)$ & $126(27.6)$ & 0.000 \\
\hline Rural & $2682(87.9)$ & $486(66.5)$ & & 2172(96.7) & $996(63.6)$ & & 2958(84.8) & $210(72.4)$ & \\
\hline \multicolumn{10}{|l|}{ Wealth index } \\
\hline Poorest & 1040(19.5) & $101(8.5)$ & 0.000 & $923(23.8)$ & $218(7.5)$ & 0.000 & 1098(18.2) & $43(6.9)$ & 0.000 \\
\hline Poorer & $569(21.6)$ & $95(11.7)$ & & $431(22.8)$ & $233(14.9)$ & & $620(20.4)$ & $44(11.6)$ & \\
\hline Middle & $539(23.1)$ & 113(15.5) & & $416(24.5)$ & $236(17.1)$ & & $601(21.7)$ & $51(21.0)$ & \\
\hline Richer & $455(19.7)$ & 126(21.6) & & $344(21.1)$ & $237(18.3)$ & & $524(19.6)$ & $57(25.6)$ & \\
\hline Richest & $644(16.2)$ & $596(42.7)$ & & $201(7.7)$ & 1039(42.2) & & 1099(20.0) & $141(34.9)$ & \\
\hline \multicolumn{10}{|l|}{ Occupation } \\
\hline Not Working & 1722(51.1) & $502(47.7)$ & 0.214 & $1263(51.9)$ & $961(48.2)$ & 0.133 & 2085(51.3) & 139(38.3) & 0.00 \\
\hline Working & 1525(48.9) & $529(52.3)$ & & $1052(48.1)$ & 1002(51.8) & & 1857(48.7) & 197(61.7) & \\
\hline \multicolumn{10}{|l|}{ Media access } \\
\hline No & 2197(67.4) & $345(41.7)$ & 0.000 & $1776(73.9)$ & $766(44.9)$ & 0.000 & $2398(64.2)$ & 144(41.9) & 0.000 \\
\hline Yes & 1050(32.6) & $686(58.3)$ & & $539(26.1)$ & $1197(55.1)$ & & 1544(35.8) & 192(58.1) & \\
\hline \multicolumn{10}{|l|}{ Distance } \\
\hline Big problem & $1726(56.5)$ & $353(40.2)$ & 0.000 & $1433(62.0)$ & $646(40.0)$ & 0.000 & 1963(54.8) & 116(35.9) & 0.000 \\
\hline No big problem & $1521(43.5)$ & $678(59.8)$ & & $882(38.0)$ & $1317(60.0)$ & & 1979(45.2) & $220(64.1)$ & \\
\hline \multicolumn{10}{|l|}{ Pregnancy wanted } \\
\hline Then & $2590(75.4)$ & $832(78.4)$ & 0.23 & $1844(75.4)$ & 1578(76.9) & 0.18 & $3154(76.2)$ & 268(72.8) & 0.025 \\
\hline Later & $419(15.7)$ & 150(15.1) & & $292(15.2)$ & $277(16.2)$ & & $521(15.1)$ & $48(22.4)$ & \\
\hline No more & $238(8.9)$ & $49(6.5)$ & & $179(9.4)$ & $108(6.9)$ & & $267(8.7)$ & $20(4.8)$ & \\
\hline \multicolumn{10}{|l|}{ Parity } \\
\hline One & 1035(29.3) & 435(38.6) & 0.000 & $572(21.8)$ & $898(45.6)$ & 0.000 & 1356(30.9) & 114(32.4) & 0.003 \\
\hline $2-4$ & $1133(36.2)$ & 419(39.4) & & $807(36.5)$ & $745(37.3)$ & & $1417(36.1)$ & 135(46.6) & \\
\hline$>=5$ & 1079(34.5) & $177(22.0)$ & & $936(41.7)$ & $320(17.1)$ & & 1169(33.0) & 87 (21.1) & \\
\hline
\end{tabular}


odds of been attended by a skilled birth attendant were lower by 51\% (AOR: 0.49; 95\% CI: 0.35-0.67) among mother who had 2-4 children compared to who had one child. Likewise, mothers who had children of 5 and above compared to mothers who had one child had a lower odds of ANC and skilled delivery by $41 \%$ (AOR: 0.59; $95 \%$ CI: $0.38-0.92$ ), and by $64 \%$ (AOR: 0.36 ; $95 \%$ CI: $0.25-0.52$ ), respectively (Table 3 ).

Model Sensitivity analysis: ANC; $78.4 \%$, skilled delivery; $75.5 \%$, and Postnatal care; $92.1 \%$.

\section{Discussion}

In my understanding, this is the primary investigation to be performed in Ethiopia to validate the relationship between health insurance enrolment and maternal healthcare service utilization. The results of this study showed that maternal health insurance status had a substantial role in the utilization of ANC and skilled delivery. In contrast, health insurance has no significant association with PNC utilization.

According to this finding, the odds of ANC utilization were higher among mothers who had health insurance,

Table 3 Multivariate analysis to identify the relationship between health insurance and maternal health care service utilization $(n=4278)$

\begin{tabular}{|c|c|c|c|c|}
\hline \multirow[t]{2}{*}{ Variables } & \multirow[t]{2}{*}{ Categories } & \multirow{2}{*}{$\begin{array}{l}\text { Recommended ANC } \\
\text { AOR;95\% Cl }\end{array}$} & \multirow{2}{*}{$\begin{array}{l}\text { Skilled delivery } \\
\text { AOR; } 95 \% \mathrm{Cl}\end{array}$} & \multirow{2}{*}{$\begin{array}{l}\text { PNC } \\
\text { AOR;95\% Cl }\end{array}$} \\
\hline & & & & \\
\hline \multirow[t]{2}{*}{ Health insurance } & No & Ref. & Ref. & Ref. \\
\hline & Yes & $1.54(1.06-2.25)^{*}$ & $1.84(1.1-3.08)^{*}$ & $1.32(0.7-2.46)$ \\
\hline \multirow[t]{4}{*}{ Age } & $15-19$ & Ref. & Ref. & Ref. \\
\hline & $20-24$ & $1.31(0.77-2.21)$ & $0.94(0.61-1.45)$ & $1.33(0.59-3.03)$ \\
\hline & $25-34$ & $2.03(1.15-3.58)^{*}$ & $1.02(0.63-1.64)$ & $0.97(0.39-2.4)$ \\
\hline & $35-49$ & $1.97(0.97-3.98)$ & $0.74(0.41-1.32)$ & $1.42(0.46-4.4)$ \\
\hline \multirow[t]{4}{*}{ Educational status } & No education & Ref. & Ref. & Ref. \\
\hline & Primary & $1.38(1.046-1.81)^{*}$ & $1.79(1.43-2.24)^{*}$ & $1.21(0.75-1.94)$ \\
\hline & Secondary & $1.57(1.02-2.42)^{*}$ & $4.84(2.89-8.9)^{*}$ & $1.20(0.59-2.44)$ \\
\hline & Higher & $2.1(1.27-3.42)^{*}$ & $6.82(3.18-14.6)^{*}$ & $1.32(0.53-3.26)$ \\
\hline \multirow[t]{3}{*}{ Marital status } & Never in union & Ref. & Ref. & Ref. \\
\hline & Currently in union & $0.42(0.17-1.00)$ & $0.6(0.21-1.74)$ & $0.75(0.23-2.47)$ \\
\hline & Formerly in union & $0.43(0.17-1.09)$ & $0.58(0.19-1.72)$ & $0.82(0.24-2.86)$ \\
\hline \multirow[t]{2}{*}{ Residence } & Rural & Ref. & Ref. & Ref. \\
\hline & Urban & $0.96(0.61-1.5)$ & $4.74(2.62-8.57)^{*}$ & $0.95(0.5-1.79)$ \\
\hline \multirow[t]{5}{*}{ Wealth index } & Poorest & Ref. & Ref. & Ref. \\
\hline & Poorer & $1.15(0.72-1.84)$ & $1.82(1.22-2.73)^{*}$ & $1.35(0.69-2.61)$ \\
\hline & Middle & $1.34(0.84-2.11)$ & $2.03(1.39-2.96)^{*}$ & $2.18(1.13-4.19)^{*}$ \\
\hline & Richer & $1.87(1.18-2.97)^{*}$ & $2.17(1.45-3.25)^{*}$ & $2.42(1.31-4.44)^{*}$ \\
\hline & Richest & $3.02(1.79-5.10)^{*}$ & $3.71(2.17-6.35)^{*}$ & $2.19(1.07-4.45)^{*}$ \\
\hline \multirow[t]{2}{*}{ Occupation } & Not Working & Ref. & Ref. & Ref. \\
\hline & Working & $0.91(0.72-1.16)$ & $1.03(0.82-1.30)$ & $1.43(1.03-1.98)^{*}$ \\
\hline \multirow[t]{2}{*}{ Media access } & No & Ref. & Ref. & Ref. \\
\hline & Yes & $1.45(1.08-1.95)^{*}$ & $1.05(0.81-1.35)$ & $1.67(1.05-2.64)^{*}$ \\
\hline \multirow[t]{3}{*}{ Distance to a health facility } & Big problem & Ref. & Ref. & Ref. \\
\hline & Not a big problem & $1.2(0.91-1.56)$ & $1.26(0.97-1.63)$ & $1.6(1.08-2.36)^{*}$ \\
\hline & No more & Ref. & Ref. & Ref. \\
\hline \multirow[t]{2}{*}{ Pregnancy intension } & Then & $1.25(0.79-1.97)$ & $0.8(0.53-1.21)$ & $1.67(0.83-3.37)$ \\
\hline & Later & $1.03(0.63-1.68)$ & $0.62(0.37-1.05)$ & $2.33(1.06-5.14)^{*}$ \\
\hline \multirow[t]{3}{*}{ Parity } & One & Ref. & Ref. & Ref. \\
\hline & $2-4$ & $0.75(0.52-1.06)$ & $0.49(0.35-0.67)^{*}$ & $1.48(0.85-2.57)$ \\
\hline & $>=5$ & $0.59(0.38-0.92)^{*}$ & $0.36(0.25-0.52)^{*}$ & $0.91(0.44-1.89)$ \\
\hline
\end{tabular}

*: shows a statistically significant association where $p<0.05$; Ref.; Reference; Goodness of fit for ANC (Cox and Snell: 0.75 ; Nagelkerke: 0.81 ; McFadden: 0.78 ), Goodness of fit for Skilled delivery (Cox and Snell: 0.64; Nagelkerke: 0.85; McFadden; 0.83), Goodness of fit for Postnatal care (Cox and Snell: 0.78; Nagelkerke: 0.83; McFadden; 0.81) 
which is consistent with a research accomplished in low and middle-income countries that the percentage of women having at least one ANC follow up was higher among women who had been covered with health insurance than their counterparts [36]. Likewise, this result is also reinforced by a study made in Gabon [24] and Ghana [30, 37, 38] in which women with health insurance are likely to have a high frequency of ANC follow-up. Generally, eliminating the economic obstacles to ANC is supposed to increase the use of ANC followup [21].

Regarding skilled delivery, the likelihoods of been attended by a skilled birth attendant were higher among mothers who were covered by health insurance. This result is steady with a study which has been done in Gabon [39], Nigeria [40], and across 3 countries (Ghana, Indonesia, and Rwanda) stated that health insurance possession significantly increased the chance of women having a birth in a health institution [20, 28, 37, 41, 42].

Similar to earlier research [43, 44], this study also revealed that obstetrics and sociodemographic factors which include; age, education level, wealth index, marital status, place of residence, distance to a health facility, media access, occupation, parity, and pregnancy intention were major forecasters of maternal healthcare service utilization. Specifically, this study also showed that the age of the mothers was one of the independent variables which affect the accomplishment rate of ANC follow-up. Mothers aged 25-34 compared to 15-19 had approximately higher probabilities of ANC service utilization. The result of this study is equivalent to earlier studies done in Cambodia [45], and Tanzania [23]. It is also supported by a study done in India in which adolescents had poor maternal healthcare utilization [46]. The consistency might be due to the older women could have bad obstetrics history in the previous pregnancy.

Similarly, women from the richest households are 3 times, more likely to use ANC and 3.7 times more likely to have skilled birth, and the likelihoods of PNC service were 2.19 times higher than poorest households which is analogous to a study done in Cambodia [45]. The similarity could be the fact that women from the wealthiest households could have learned, empowered, and get information about the complication of pregnancy, and therefore they follow continuum maternal healthcare service utilization.

Regarding educational status, the odds of ANC service and skilled delivery utilization were higher among women who attended primary, secondary, and higher education, respectively compared to non-educated ones. This finding is also in line with other studies done in Tanzania [23], and Uganda [47] Ethiopia [48].

Moreover, mothers living in an urban area had higher chances of been attended by a skilled birth attendant compared to rural residents, which are contradicted the study done in Tanzania [23] in which women of urban areas had lower odds of been attended by a skilled birth attendant. The discrepancy might be due to variation in socio-demographic factors.

Furthermore, the likelihoods of suggested ANC and PNC use were higher among mothers who accessed media compared to their counterparts, which is also reinforced by a study done in a developing country [43, 44]. Similarly, skilled delivery was lower among mothers who had 2-4 children than mothers who had one child. Likewise, mothers who had children of 5 and above compared to mothers who had one child had a lower odds of ANC and skilled delivery which is consistent with a study done in Cambodia [45], which implies women who had less order birth are significantly related with frequency of ANC follow up and their persistence to use skilled delivery. But this finding is contradicted with a study done in Tanzania [23] which stated women with grand para were more likely to have more information of predisposing factors and then they were followed to recommend continuum maternal healthcare.

Finally, this research revealed that pregnancy intention, occupation, and remoteness to health facilities were also significantly related to PNC use. Mothers who did not desire their pregnancy were more likely to use PNC at health institutions than their counterparts, which is reinforced by a study done in Ethiopia [49]. The consistency might be explained by fear of problems emerging after birth among mothers with undesired pregnancies. Likewise, mothers who had no big problem reaching a health institution were more likely to adhere to PNC utilization than those who had a big challenge to arrive at the health facility. This finding is contradicted with a study done in the Tigray region [50] which reported that the proximity of women to health institutions had an adverse relationship with the rate of PNC use. This could be clarified that individuals residing near to health institution might be developed poor healthseeking behavior. Moreover, mothers who are working their business were more likely to use PNC service than those who did not work their business which is supported by a study done in Uganda [51].

\section{Strength and limitation of the study}

The strength of this study was the authors' had been used nationally representative data from a consistent data set with the best response rates. Despite the findings of the study are precious for designing strategy and policy there are some critical barriers. As an example, the information composed is self-stated, which is liable for reporting errors and biases. Since it is a crosssectional study, we could not assign causation to any of the relations among the known causes and the 
dependent variable. Nevertheless, this study is one of the few that has contributed in perspective of insurance enrolment and maternal health care service use among women in Ethiopia.

\section{Conclusions}

This research showed that women enrolled in health insurance were associated with skilled delivery and recommended ANC utilization than women who did not enrolment in health insurance. Additionally, obstetrics and socio-demographic factors which include; age, education level, wealth index, marital status, place of residence, distance to a health facility, media access, occupation, parity, and pregnancy intention were substantial factors of maternal healthcare service utilization. So, improving health insurance coverage alone might not get the desired outcome in all maternal health services. It is also a critical issue to address the tackles of the entire health system to have an excellent maternal healthcare service in Ethiopia. The Ethiopian government should provide and strengthen health insurance enrolment for pregnant women especially those of lower socioeconomic status, uneducated women, those who had no access to media, those who were living far from health facilities, and women residing in rural areas. Healthcare providers should be strengthening health insurance coverage to enhance institutional delivery. Additionally, government and stakeholders' efforts should be strengthened to stepping-up health insurance on uneducated and rural women in the lowest wealth quantile.

The findings of this study will also guide policymakers to develop an appropriate strategy and implementation plan about how good health insurance coverage affects the quality of maternal health services utilization.

\section{Recommendation for public health actions}

The health care provider should provide knowledge about the significance of health insurance especially for those individuals who have low socioeconomic status and the rural residents.

Future researches should focus on assessing the usefulness of health insurance programs in endorsing maternal health service utilization among diverse socioeconomic populations using a strong research design.

\footnotetext{
Abbreviations

AOR: Adjusted Odds Ratio; ANC: Antenatal Care; Cl: Confidence Interval; EDHS: Ethiopian Demographic Health Survey; EAs: Enumeration Areas; PHC: Population and Housing Census; MMR: Maternal Mortality Ratio; PNC: Postnatal Care; SPSS: Statistical Package Software for Social Science; UHC: Universal Health Coverage; WHO: World Health Organizations
}

\section{Acknowledgments}

we are thankful to the USAID-DHS program for gaining admission to the 2016 Ethiopian Demographic Health Survey.

\section{Authors' contributions}

AS: apprehended the research idea, accompanied data extraction, data analysis, and data clarification, wrote and revised the paper. MA: conducted data extraction, reviewed and approved the final manuscript. All authors have read and approved the manuscript.

\section{Funding}

There is no funding to report.

\section{Availability of data and materials}

We recycled the USAID-DHS program 2016 Ethiopian demographic and health survey data set. To request the similar or altered data for another purpose, a new research project request should be succumbed to the DHS program here: https://dhsprogram.com/data/available-datasets.cfm

The DHS Program will normally assess all data requests within $24-48 \mathrm{~h}$ (during working days) and provide notification if access has been approved, or other project information is needed before access can be granted. After getting consent, the investigator can log in and choose the specific data in the format they favor.

\section{Declarations}

\section{Ethics approval and consent to participate}

Ethical permission for the study is not essential since it is a secondary data analysis from EDHS 2016 database. The investigators have gotten the survey data from the USAID-DHS program and then the investigators of this study have preserved the privacy of the data. The oral agreement was gotten from the study members due to the high percentage of illiteracy before the beginning of the study.

\section{Consent for publication}

Not applicable.

\section{Competing interests}

We approve that this research is our original paper and that there is no conflict of interest in this work.

\section{Author details}

${ }^{1}$ Department of Midwifery, Woldia University, Woldia, Ethiopia. ${ }^{2}$ Department of Public Health, Woldia University, Woldia, Ethiopia.

Received: 7 September 2020 Accepted: 25 October 2021

Published online: 30 December 2021

\section{References}

1. Tang D, Gao X, Coyte PC. The effects of compulsory health insurance on birth outcomes: evidence from China's UEBMI scheme. BMC Health Serv Res. 2019;19(1):779. https://doi.org/10.1186/s12913-019-4657-1.

2. Were LPO, Were E, Wamai R, Hogan J, Galarraga O. The Association of Health Insurance with institutional delivery and access to skilled birth attendants: evidence from the Kenya demographic and health survey 200809. BMC Health Serv Res. 2017;17(1):454. https://doi.org/10.1186/s12913-01 7-2397-7.

3. Shelton JD. Ensuring health in universal health coverage. Nature. 2013; 493(7433):453.

4. Organization $\mathbf{W H}$. The world health report: health systems financing: the path to universal coverage: executive summary. World Health Organization; 2010.

5. Verguet $\mathrm{S}$, Olson ZD, Babigumira JB, Desalegn D, Johansson KA, Kruk ME, et al. Health gains and financial risk protection afforded by public financing of selected interventions in Ethiopia: an extended cost-effectiveness analysis. Lancet Glob Health. 2015;3(5):e288-e96. https://doi.org/10.1016/ S2214-109X(14)70346-8.

6. Dussault G, Dubois C-A. Human resources for health policies: a critical component in health policies. Hum Resour Health. 2003;1(1):1. https://doi. org/10.1186/1478-4491-1-1.

7. Roberts $M$, Hsiao W, Berman P, Reich M. Getting health reform right: a guide to improving performance and equity. Bull World Health Organ. 2006; $84(2)$ 
8. Organization WH. Trends in maternal mortality: 1990 to 2013: estimates by WHO, UNICEF, UNFPA, the World Bank and the United Nations population division: executive summary. World Health Organization; 2014.

9. Hill PS, Buse K, Brolan CE, Ooms G. How can health remain central post2015 in a sustainable development paradigm? Glob Health. 2014;10(1):1-5. https://doi.org/10.1186/1744-8603-10-18.

10. Organization WH. Health Accounts. Global health expenditure database. Geneva: World Health Organization; 2012. www.who.int/nha/country/en/ index.html. Accessed 28 Dec 2020. Report No.: 0277-9536.

11. Organization WH. New guidelines on antenatal care for a positive pregnancy experience, 2016.

12. Central Statistical Agency (CSA) [Ethiopia] and ICF. Ethiopia Addis Ababa E, and Rockville, Maryland, USA, CSA, and ICF. Demographic and Health Survey; 2016.

13. Mekonnen W, Gebremariam A. Causes of maternal death in Ethiopia between 1990 and 2016: systematic review with meta-analysis. Ethiop J Health Dev. 2018;32(4).

14. Berhan Y, Berhan A. Commentary: reasons for persistently high maternal and perinatal mortalities in Ethiopia: part III-perspective of the "three delays" model. Ethiop J Health Sci. 2014;24(0):137-48. https://doi.org/1 0.4314/ejhs.v24i0.12S.

15. Endalkachew. Aassessment of manucipal solid waste management practice: A case study of bishoftu city administration. 2018.

16. Shah N, Palan S, Mahajan A, Shah P, Shah R, Kumar P. Why and how maxillofacial disability and impairment due to trauma should be quantified for compensation: a need for nationwide guidelines. J Maxillofac Oral Surg. 2014; 13(4):425-30. https://doi.org/10.1007/s12663-013-0527-2.

17. Alebachew A, Hatt L, Kukla M. Monitoring and evaluating progress towards universal health coverage in Ethiopia. PLoS Med. 2014;11(9):e1001696. https://doi.org/10.1371/journal.pmed.1001696

18. Onarheim KH, Taddesse M, Norheim OF, Abdullah M, Miljeteig I. Towards universal health coverage for reproductive health services in Ethiopia: two policy recommendations. Int J Equity Health. 2015;14(1):86. https://doi.org/1 0.1186/s12939-015-0218-3.

19. Nageso D, Tefera K, Gutema K. Enrollment in community based health insurance program and the associated factors among households in Boricha district, Sidama zone, southern Ethiopia; a cross-sectional study. PLoS One. 2020;15(6):e0234028. https://doi.org/10.1371/journal.pone.0234028.

20. Khan SM, Singh K. The association between health insurance coverage and skilled birth attendance in Ghana: a National Study. Matern Child Health J. 2016;20(3):534-41. https://doi.org/10.1007/s10995-015-1851-6.

21. Gouda HN, Hodge A, Bermejo R 3rd, Zeck W, Jimenez-Soto E. The impact of healthcare insurance on the utilisation of facility-based delivery for childbirth in the Philippines. PLoS One. 2016;11(12):e0167268. https://doi. org/10.1371/journal.pone.0167268.

22. Comfort $A B$, Peterson LA, Hatt LE. Effect of health insurance on the use and provision of maternal health services and maternal and neonatal health outcomes: a systematic review. Journal of health, population, and nutrition. 2013;31(4 Suppl 2):S81.

23. Kibusi SM, Sunguya BF, Kimunai E, Hines CS. Health insurance is important in improving maternal health service utilization in Tanzania-analysis of the 2011/2012 Tanzania HIV/AIDS and malaria indicator survey. BMC Health Serv Res. 2018;18(1):112. https://doi.org/10.1186/s12913-018-2924-1.

24. Sanogo NA, Yaya S. Wealth Status, Health Insurance, and Maternal Health Care Utilization in Africa: Evidence from Gabon. 2020;2020:4036830.

25. Yaya S, Da F, Wang R, Tang S, Ghose B. Maternal healthcare insurance ownership and service utilisation in Ghana: analysis of Ghana demographic and health survey. PLoS One. 2019;14(4):e0214841. https://doi.org/10.1371/ journal.pone.0214841.

26. Kuwawenaruwa A, Mtei G, Baraka J, Tani K. The effects of MCH insurance cards on improving equity in access and use of maternal and child health care services in Tanzania: a mixed methods analysis. J Health Popul Nutr. 2016;35(1):37.

27. Brugiavini A, Pace N. Extending health insurance in Ghana: effects of the National Health Insurance Scheme on maternity care. Heal Econ Rev. 2016; 6(1):7. https://doi.org/10.1186/s13561-016-0083-9.

28. Browne $J$, Kayode GA, Arhinful D, Fidder SA, Grobbee DE, KlipsteinGrobusch K. Health insurance determines antenatal, delivery and postnatal care utilisation: evidence from the Ghana demographic and health surveillance data. BMJ Open. 2016;6(3):e008175. https://doi.org/10.1136/ bmjopen-2015-008175.
29. Brooks MI, Thabrany H, Fox MP, Wirtz VJ, Feeley FG, Sabin LL. Health facility and skilled birth deliveries among poor women with Jamkesmas health insurance in Indonesia: a mixed-methods study. BMC Health Serv Res. 2017; 17(1):105. https://doi.org/10.1186/s12913-017-2028-3.

30. Arthur E. Wealth and antenatal care use: implications for maternal health care utilisation in Ghana. Health Econ Rev. 2012;2(1):14. https://doi.org/10.11 86/2191-1991-2-14.

31. Amoakoh-Coleman M, Ansah EK, Agyepong IA, Grobbee DE, Kayode GA, Klipstein-Grobusch K. Predictors of skilled attendance at delivery among antenatal clinic attendants in Ghana: a cross-sectional study of population data. BMJ Open. 2015;5(5):e007810. https://doi.org/10.1136/bmjopen-2015007810.

32. Organization $\mathrm{WH}$. WHO recommendations on antenatal care for a positive pregnancy experience. World Health Organization; 2016.

33. Fekadu M, Regassa N. Skilled delivery care service utilization in Ethiopia: analysis of rural-urban differentials based on national demographic and health survey (DHS) data. Afr Health Sci. 2014;14(4):974-84. https://doi.org/1 0.4314/ahs.v14i4.29.

34. Sines E, Syed U, Wall S, Worley H. Postnatal care: A critical opportunity to save mothers and newborns. Policy Perspect Newborn Health. 2007;1(7).

35. Craney TA, Surles JG. Model-dependent variance inflation factor cutoff values. Qual Eng. 2002;14(3):391-403. https://doi.org/10.1081/QEN-120001 878.

36. Wang W, Temsah G, Mallick L. Health insurance coverage and its impact on maternal health care utilization in low-and middle-income countries. ICF international; 2014.

37. Twum P, Qi J, Aurelie KK, Xu L. Effectiveness of a free maternal healthcare programme under the National Health Insurance Scheme on skilled care: evidence from a cross-sectional study in two districts in Ghana. BMJ Open. 2018;8(11):e022614. https://doi.org/10.1136/bmjopen-2018-022614.

38. Owoo NS, Lambon-Quayefio MP. National health insurance, social influence and antenatal care use in Ghana. Health Econ Rev. 2013;3(1):19. https://doi. org/10.1186/2191-1991-3-19.

39. Sanogo NA, Yaya S. Wealth status, health insurance, and maternal health care utilization in Africa: evidence from Gabon. Biomed Res Int. 2020;2020: 4036830.

40. Brals D, Aderibigbe SA, Wit FW, van Ophem JCM, van der List M, Osagbemi GK, et al. The effect of health insurance and health facility-upgrades on hospital deliveries in rural Nigeria: a controlled interrupted time-series study. Health Policy Plan. 2017:32(7):990-1001. https://doi.org/10.1093/heapol/ cZX034.

41. Wang $W$, Temsah $G$, Mallick $L$. The impact of health insurance on maternal health care utilization: evidence from Ghana, Indonesia and Rwanda. Health Policy Plan. 2017;32(3):366-75. https://doi.org/10.1093/heapol/czw135.

42. Suparmi IBM, Lestari $\mathrm{H}$. Health insurance as a solution for barriers to maternal healthcare access in Indonesia. 2019.

43. Kebede A, Hassen K, Nigussie TA. Factors associated with institutional delivery service utilization in Ethiopia. Int J Women's Health. 2016;8:463-75. https://doi.org/10.2147/IJWH.S109498.

44. Simkhada B. Teijlingen ERv, porter M, Simkhada P. factors affecting the utilization of antenatal care in developing countries: systematic review of the literature. J Adv Nurs. 2008;61(3):244-60. https://doi.org/10.1111/j.1365-2 648.2007.04532.x

45. Wang W, Hong R. Levels and determinants of continuum of care for maternal and newborn health in Cambodia-evidence from a populationbased survey. BMC pregnancy and childbirth. 2015;15(1):62. https://doi.org/1 0.1186/s12884-015-0497-0.

46. Singh PK, Rai RK, Alagarajan M, Singh L. Determinants of maternity care services utilization among married adolescents in rural India. PLoS One. 2012;7(2):e31666. https://doi.org/10.1371/journal.pone.0031666.

47. Bbaale E. Factors influencing timing and frequency of antenatal care in Uganda. Australas Med J. 2011;4(8):431-8. https://doi.org/10.4066/AMJ.2011. 729.

48. Fekadu GA, Ambaw F, Kidanie SA. Facility delivery and postnatal care services use among mothers who attended four or more antenatal care visits in Ethiopia: further analysis of the 2016 demographic and health survey. BMC Pregnancy Childbirth. 2019;19(1):64. https://doi.org/10.1186/s12 884-019-2216-8.

49. Ayele BG, Woldu MA, Gebrehiwot HW, Gebre-egziabher EG, Gebretnsae H, Hadgu T, et al. Magnitude and determinants for place of postnatal care utilization among mothers who delivered at home in Ethiopia: a 
multinomial analysis from the 2016 Ethiopian demographic health survey. Reprod Health. 2019;16(1):162. https://doi.org/10.1186/s12978-019-0818-2.

50. Abraha TH, Gebrezgiabher BB, Aregawi BG, Belay DS, Tikue LT, Reda EB. Factors associated with compliance with the recommended frequency of postnatal Care Services in Four Rural Districts of Tigray region, North Ethiopia. Korean J Fam Med. 2019;40(5):329-34. https://doi.org/10.4082/ kjfm.18.0023.

51. Ndugga P, Namiyonga NK, Sebuwufu D. Determinants of early postnatal care attendance: analysis of the 2016 Uganda demographic and health survey. BMC Pregnancy Childbirth. 2020;20(1):1-14. https://doi.org/10.1186/ s12884-020-02866-3.

\section{Publisher's Note}

Springer Nature remains neutral with regard to jurisdictional claims in published maps and institutional affiliations.

Ready to submit your research? Choose BMC and benefit from:

- fast, convenient online submission

- thorough peer review by experienced researchers in your field

- rapid publication on acceptance

- support for research data, including large and complex data types

- gold Open Access which fosters wider collaboration and increased citations

- maximum visibility for your research: over $100 \mathrm{M}$ website views per year

At BMC, research is always in progress.

Learn more biomedcentral.com/submissions 